\title{
Dreams from Another Dimension?
}

\author{
Stanley Krippner, PhD \\ Saybrook University
}

\begin{abstract}
In 2015, I began communicating with an events planner for the U.S. Army who shared with me a series of anomalous dreams-anomalous in the sense that the dreams usually contained specific names of deceased servicemen previously unknown to her but known to an assistant chaplain with whom she worked. The goal of my ensuing case study research into this apparent episode of spontaneous mediumship was to collect these dreams, search for commonalities, and propose explanations for their anomalous aspects. Alternative explanations included fraud, faulty memory, coincidence, and telepathy or some other form of remote perception. None of these alternatives explained these anomalies as well as what the experiencer herself proposed: that the deceased themselves had successfully communicated with her during her nighttime dreams.
\end{abstract}

KEY WORDS: dreams, mediumship, after-death communication, post-mortem survival, U.S. Army deaths

The possibility of life after death has intrigued human beings for millennia. It was the impetus for the founding of the Society for Psychical Research, the oldest organization that has attempted to bring a scientific perspective to the study of post-mortem survival and other issues that challenge Western paradigms (Stemman, 2005). Disciplined research on the topic, which has provoked controversy, has produced inconsistent results (e.g., O’Keefe \& Wiseman, 2005; Schouten, 1994). That research has included cases of perceived communication between living and deceased persons. Such cases include both spontaneousunplanned and unexpected—contact and intentional contact, in addi-

Stanley Krippner, PhD, is Alan Watts Professor of Psychology at Saybrook University, Oakland, CA. He is co-author of Extraordinary Dreams and How to Work With Them and Haunted by Combat: Understanding PTSD in Veterans and co-editor of Varieties of Anomalous Experience: Examining the Scientific Evidence. The preparation of this article was supported by the Saybrook University Chair for the Study of Consciousness. Correspondence regarding this article should be sent to Dr. Krippner at email: skrippner@saybrook.edu. 
tion to contact involving messages intended for the living experiencer as well as those intended for a third party-in which cases the experiencer served as a medium of communication between the deceased and the third party (Guggenheim \& Guggenheim, 1995; Streit-Horn, 2011). In the English language, the word "medium" has been used to describe people who claim to possess abilities that allow them to intentionally contact and receive information from the deceased. However, there are individuals who do not refer to themselves as mediums but who have had spontaneous experiences in which allegedly a deceased person, uninvited, has given them information regarding or intended for a third party that has been verified by subsequent events. Research has revealed this phenomenon to occur increasingly in the aftermath of near-death experiences (NDEs; Holden, Foster, \& Kinsey, 2014). However, some individuals report this phenomenon in the absence of a history of NDEs. One of those individuals, whom I will call "Amanda," contacted me knowing of my research on post-mortem survival and related topics.

Following is a case study of Amanda's experiences. The study consisted primarily of several months of correspondence with Amanda and a 30-minute Skype interview with the third person, Wink, who seemed to be the referent for the information Amanda received in her dreams. In that interview, Wink confirmed all aspects of what Amanda had reported and did not present any information that contradicted it.

At the time of our correspondence, Amanda had for several years been an events planner for the U.S. Army, coordinating events for "relationship enrichment programs" such as retreats for both married and unmarried soldiers. In addition, she worked with Army chaplains. Her father was an ordained minister, and in her youth she had attended Protestant worship services-most of them non-denominational. As a child, she recalled several dreams that were related to religious themes, as well as dreams that appeared to forecast future events and lucid dreams in which she realized she was dreaming (Krippner, Bogzaran, \& de Carvalho, 2002). In addition, Amanda had a few dreams about deceased family members. In one of them, her grandmother (of Native American descent) told her that she understood why Amanda could not be present when she passed, a circumstance that the young girl had regretted.

In the course of Amanda's work with the U.S. Army, she met Wink, who had been a chaplain's assistant for several years. About six months after she had started assisting Army chaplains, Amanda began hav- 
ing unusual dreams and started telling them to Wink. She did not tell Wink all of her dreams but only those involving what she called a "definite compulsion" to share them with her co-worker. These dreams contained specific names and other information that could be verified.

None of Amanda's previous dreams were as vivid or powerful as those she had over the three years prior to this writing. Amanda contacted me early in 2015 and has given me written permission to use her dream reports in my ongoing research concerning anomalous dreams. Our correspondence has been by email, and all the names in this report are fictitious. Several other measures have been taken to preserve anonymity.

Amanda wrote me that her first anomalous dream in the series occurred about six months after she met Wink, a Native American from Arizona. According to Amanda, Wink's clan has an unusual language, very different from the Navajo language spoken by his father. As Wink put it in his Skype interview with me, he was "raised as a warrior" and was told by his elders that he had been given "the gift of discernment." He also told me that his service as an assistant chaplain stemmed from the knowledge and spiritual counsel he had received from Native American elders over the course of his life.

While deployed in Iraq and Afghanistan he was injured several times, and on several of these occasions he had near-death experiences (NDEs). The NDEs followed two occasions when he was shot and sustained severe physical injuries and also followed helicopter crashes, firefights, bombings, and detonations of improvised explosive devices. He also had survived combat attacks that were not accompanied by NDEs. However, he estimated that he had about 30 NDEs during attacks that could have been fatal. His tribal elders had discouraged him from discussing the contents of these experiences.

According to Amanda, Wink has held a conversation with tribal elders in which he told them about Amanda's dreams. They replied that her ability was the complementary gift to his, and they gave him permission to discuss these dreams. Wink had just begun to tell Amanda about his military career and his overseas service when she had her first dream of the series.

\section{The Dreams}

Following are Amanda's reported dreams and comments verbatim from our correspondence. In each case, Amanda's dream appears in italicized font, and her commentary appears in regular font. 


\section{Case One}

I am walking across the road to see a friend's new house. Before I can return to my house, I have to go through a building. I am in an American Legion building, where I start playing bridge with two ladies. One lady is in her late 50s, and the other is her mother, about 80. I tell them I am from Kentucky, and then the daughter remarks that her mother collects business cards from the record stores she visits in Louisville. She hands me a stack of cards and in the middle is a lanyard with the name "Sanchez" on it. I recall that all of the Special Operations personnel have to wear identification lanyards while they are in their compound. I call Wink so that he can see what is in my hand. He says, "I'll be right there." I look on the other side of the lanyard, and there is a picture of a rattlesnake with a knife through its tail. Wink then comes into the building, hugs the two ladies, and walks off with them. Then I wake up.

The next morning I called Wink on his way to work and told him a little about my dream. He came right over to my house. He told me that one of his friends, Jeremy Sanchez, was killed in 2004. The only surviving members of his immediate family were his mother and grandmother. Before Jeremy was killed, he was auditioning for a spot in a Special Operations unit. The symbol of the unit he wanted to be in was a rattlesnake with a sword in its tail.

\section{Case Two}

In this dream, I am arguing with Wink about the location of a venue for a special event. Then I go walking down a hallway in a property where I've coordinated events in the past. I go into a large suite where a couple of sleeping rooms share a common parlor area. As I walk into the parlor, a man is sitting on a sofa. I sit down and start talking to him about the nature of his work. I also want to share with him my connection with the Special Operations aviation world and with Wink. He hands me a manila folder and I see a name on the side. It is "Bandrews."

When I told Wink about this dream, he told me that a pilot friend of his had died on a mission. It was the first time that a manifest had been done in a way that would add the first two letters of the first name onto the soldier's last name. Britt Andrews was the pilot on that mission, but, due to the manifest change, he was listed as "Bandrews." The manifest should have read "Brandrews," but someone had made a mistake. 


\section{Case Three}

This dream included several people. I hear a missile siren and dive into a nearby building. It is like an old college dormitory filled with young men. I realize it is a fraternity. I look in one room, and a bunch of guys are together playing video games and talking. I ask for someone, and they tell me his room is next door. I knock on his door, and his roommate says that he is in the gymnasium. I walk into the gym and see a group of guys standing at a desk at one end of the open gym. I ask if I can toss the football around with them, and we make small talk. One guy says his name is "Larry," another introduces himself as "Adam," and then I say I am looking for "Patrick." They say, "He's over there," and I see a guy sitting with a girl in his lap. I say "Hello," but tell them that he is not the "Patrick" I am looking for.

When I told Wink about the dream, I mentioned that I had a "Larry," an "Adam," and two "Patricks" in it. Wink was disconcerted. He told me that all of these names were the same as members of a group of Rangers he knew. "Larry" and "Adam" were both killed in IED attacks. Wink had to bring "Larry" to the hospital in two pieces. The two "Patricks" grew up in the Ranger Regiment together. The first "Patrick" went into battle and was shot. The second "Patrick" ran in to save him and was carrying him out when he was fatally shot. The first "Patrick" died of blood loss. Wink said that the first "Patrick" was his roommate in Ranger school, and that "Patrick" had pictures of him and his fiancée around his bed. Wink remembered that, in every picture, "Patrick's" fiancée was sitting on his lap.

\section{Case Four}

Wink and I are upstairs, standing in my bedroom. We are having a conversation about a new end table. He keeps trying to open the blinds, but I tell him not to, because I do not like people being able to see into my room. But then he looks down and sees someone whom he starts helping up the wall and into the window. Wink looks at me, puzzled, because he's surprised that he is seeing a man he knows is deceased. But they start talking about random things, and the man sits on the floor of my bedroom. A woman comes in and sits down, and two kids start climbing on him. He says that it's time for him to go. Wink looks at him and asks me in an aside if I see the scars on his face. I hadn't until he mentioned them. Then I see scars on the right side of his face, a big one by his eye and smaller ones on his mouth and cheek. We then start walking down the stairs with him. He starts complaining that this right hip is hurting, and I give him support as we're walking and reassurance that he will be home soon. I sit him in an old chair at what would be the front door of my house. As he sits down, I take Wink by the hand and tell him that we need to leave him. 
When I spoke to Wink about the details of this dream, he said that it sounded like Evan Greene, a Navy SEAL he was very close to. The SEAL, in fact, did have two children. His right eye was a glass eye, and there were scars on the right side of his face from catching shrapnel. The fight he ultimately died in was in a mountainous region of Afghanistan, when he climbed up a wall and sat as a decoy so that the rest of his team could take over the building. He was shot 17 times. As for the front door of our house, Wink and I had blessed that door with sage so it would be the only entrance through which spirits are supposed to enter.

\section{Case Five}

I am standing in a building that looks like the repair area of a car dealership. I am about to have an altercation with a very rude man when some gentleman in uniform walks in to intervene for me. I start talking to a man wearing an old green Army uniform and immediately have the thought that he must have been in Panama or Grenada because he is an older man. He is quite a character, making jokes and giving me medical advice, telling me that my Army Ranger friend who struggles with PTSD might want to try taking "St. Jessie's wort." So I figure that his name is Jesse or Jess.

Sometime after I woke up, I told Wink that someone named Jesse visited me and wanted him to try taking St. Jessie's wort, adding that he was from the Panama or Grenada era when there were U.S. military interventions there. Wink said that there were only a few units that were involved in those conflicts. The 75th Ranger Regiment was one of them, so I looked up Rangers who were killed in action in both interventions. There was only one Jess whom I found. His name was Jess Lucas, and he was a medic who died in the invasion of Panama. Wink did not know Jess personally, but I felt compelled to share this dream with him. Wink helped me identify the correct Ranger Regiment, something I might not have been able to do on my own.

\section{Case Six}

Not all my anomalous dreams are about Wink's wartime buddies:

In one dream, I am talking to Wink about a trip he is making back home to Arizona. We are looking at a map, when the name of a city jumps out at me. It is "Abuela," which I know is "grandmother" in Spanish. Later in the dream I am standing at a four-sided table with Wink's mom and an older lady. When I am standing next to her, the older lady gives me a small brown book with a white rosary tucked inside. Even though I don't understand the words in the book, I have a 
feeling that they are prayers. Knowing what a great honor it is to have their language shared with me, I take a quick look and then pass the book back to her.

I told Wink about this dream and texted his mother as well. She sent me a picture of an elderly lady and said it was her grandmother, the woman who had raised her. She said that her grandmother always had a prayer book with her, and she also sent a picture of her white rosary. Earlier, Wink had confirmed that the elderly lady in my dream sounded like his great-grandmother, Manzanita.

\section{Case Seven}

I woke up completely startled when my dog started howling in her sleep. I dozed back off and had a dream that I was playing laser tag with some Ranger who had a large scroll tattoo on the back of his neck. I woke up and sent Wink a message telling him about the dream at 5:45. He said that he didn't know any Rangers with scroll tattoos on the back of their neck. I went back to sleep and had another dream that I walked in on Wink in a room. He looked angry with me and came at me. He reached out for me. He looked like he was going to choke me. As he reached out for me, I told myself "You have to wake up! You're both having the same dream!" As we hit the ground, I woke up. That was around 8:30.

Wink called on his way to work and I was just telling him about the latter dream when he said, "Ummm, was that after the message you sent me about the Ranger? Because I had a dream that I was choking you when I dozed back off after your message. That was when my alarm went off about 8:30." Then he proceeded to tell me how rough the night was, especially after his younger daughter woke him up after having a nightmare and crying around 2:00.

These dreams fall into a category that is often referred to as "mutual dreams" (Krippner, Bogzaran, \& de Carvalho, 2002). If Amanda's report is accurate, the two dreams might signify her shared connection with Wink. The Ranger might have symbolized a call for Amanda to pay attention to her dreams that night. Amanda stated, "I could write it off as coincidence" but doubted that such a simple explanation would apply.

\section{Case Eight}

I am sitting in a Starbucks, texting Wink about a memorial I just saw. It was four walls in a square with each branch of the military on a side. 
I had glanced at the Army side, and then looked at the Marine Corps side. The name "Terrace" stood out to me. As I was walking away from the wall, I said to myself that maybe I should try to get the first name off of it as well, but was only able to catch a quick glimpse. I saw "Lance," but said to myself that it may have been "Vance" or something else since one of Wink's other lost soldier's names was "Lance." I was wondering if I had projected that other name into this dream.

After I woke up, I sent Wink a text telling him that a Marine named "Terrace" stood out in my dream. He sent me a message back telling that he really didn't know any Marines that were KIA (killed in action), so I thought that I should investigate. I did a search for Marines killed in action named Terrace. The first result was Lance Corporal Jeremy Terrace, who was killed in Iraq. I went straight to Wink's office and told him that. He looked at me and said, "Was he killed in the Anbar province of Iraq?" I didn't see that detail at first so I pulled it up on my phone and saw that he absolutely was. I asked Wink if he had searched it and he said, "No, I was there taking care of the personal effects of one of the guys I lost. There were three Marines that were in the 'freezer' with him. What was the date? I told him March 14, 2005 and he confirmed that it was indeed him.

\section{Case Nine}

The case of the mutual dream happened again this morning [4 July 2015]:

Wink and I were both dreaming of a combat situation where bodies were lying everywhere. I told myself, just like the others, that he was dreaming the same thing. But I also told myself that the nightmare doesn't go away when he wakes up.

We kept messaging each other about it now, and he said that he was dreaming of April 2004. It was on an Easter Sunday when this incident occurred, and it still haunts him.

\section{Case Ten}

I'm standing out in a pretty open space, like a field of some sort, watching terrorists try to execute people. I have a gun and I'm aiming directly at them, but I can't fire it. The terrorists are not trying to attack me, but I know that I need to get out of there. I see an older covered Army truck in the distance, so I run to flag it down. There is a female driving it and she tells me to get in. Immediately, I have a scared and uneasy feeling as I'm stepping up into the truck. I look in the back and she has dead bodies piled up. She says that she is in the medical field 
and it is her job to go around picking them up, and she adds "it gets lonely out here."

I woke up and contacted Wink. He asked if she was a dark-skinned woman. I told him that I didn't remember exactly. He said that while he was "in country" on the Jessica Lynch mission, they dug up a woman in a soccer field. He said she would randomly show up in his dreams and by her actions in his dream, he thought that she was there "collecting souls."

This is one of the very few dreams where I've had a negative feeling about people in my "conduit" dreams. I had two other similar dreams but this was the most prominent. Wink reached one of his tribal elders and came over today to re-sage and bless the house. We felt that we needed to cleanse and purify the house if I had something that managed to follow me back from these dreams.

\section{Case Eleven}

I haven't had much time to write since I began my new job, but I thought I would take a moment to let you know about my latest dream:

I was looking down from a helicopter that was flying over a river in a canyon. There was a large bridge crossing the river and a U.S. militarized truck driving on a road in the center of a step cliffside to the left. I could hear the conversation between the servicemen in the helicopter and the men in the truck. It was Wink at the gun in the truck and he was asking if he could shoot the bridge yet. Apparently the guys in the bird were his eyes down the river. They were all business, but at the same time very lighthearted and comical-like I've learned those guys to be. The man in the helicopter told him "it's all yours baby!" Then Wink made a kissing noise as he pulled the trigger. Down the river, I could see the bridge. It was a drawbridge, but not like one I've ever seen. Instead of the sides folding down, the center was raised, almost like a second level, and then would drop to the lower bridge level. There was graffiti and what looked like a Pi symbol in the center. When Wink pulled the trigger, the round hit the top of the drawbridge and it dropped onto the terrorists below who were trying to blow up the bridge. Once that happened, there were men in wet suits who jumped into the water looking for the bodies. I knew that they were supposed to be SEALs.

I told Wink about it later that day. And he told me that it was a mission he was on with a SEAL named Nick McNeal. The Pi symbol I saw on the bridge was actually a Roman numeral II. McNeal survived that operation but died later on a rooftop after lying on a grenade to save Wink and the other operators. Part of the movie "Act of Valor" was based on that incident. The Roman numeral wasn't particularly 
significant to the dream but more so, was actually on the real bridge where the mission took place. Wink said that there were a few of those types of drawbridges in that part of the world but that particular one had a II on it. That's how he knew who I was dreaming about.

\section{Amanda's Comments}

These dreams are usually about deceased persons whom Wink knew, most of them soldiers with whom he had served. He himself was actually in almost all the battles in which they died. I never see anything bloody or violent, though. The dreams take place in a casual setting. I've learned that the dreams with specific names and details that I remember after waking are the ones I should relay to Wink.

Despite the brutal and violent ways in which these soldiers died, they always appear perfectly healthy in my dreams and in good spirits. I feel that they are trying to reach out to Wink to tell him that they are fine and not in the condition in which he last saw them. Perhaps his guilt and overwhelming feelings cloud his abilities to have these dreams himself, and so they come through me.

\section{Discussion}

The literature on mediumship, channeling, and survival of consciousness after death reveals that some individuals seem to have the capacity to serve as conduits with the deceased and some do not. From this perspective, the case could be made that Amanda falls into the former category and Wink into the latter. If a deceased person wanted to contact Wink, he or she might discover that Wink was not a suitable conduit. However, that deceased person might search for a more suitable conduit, someone close to Wink who would be able to incorporate messages into nighttime dreams. Hence, Amanda could have been selected as an appropriate candidate for these messages from another dimension. This triangle seems to have worked remarkably well over the three years leading up to the writing of this article.

Wink's NDEs may have played a vital part in these accounts. The case could be made that although the deceased persons could not contact Wink directly, they chose Amanda, someone close to Wink who had a history of anomalous experiences. Perhaps his NDEs predisposed him to be open to anomalous experiences and, hence, a receptive partner in this communication, indeed, an essential partner because he had known virtually all of the deceased persons who appeared in Amanda's dreams. Wink told both Amanda and me that he had been "raised as a warrior" and that he had been given the "gift of discern- 
ment." As a result, there may well have been initiation experiences that helped him survive his potentially fatal combat assaults and injuries. In retrospect it can be seen that both Wink and Amanda had a background of life experiences that made them a likely pair for these reported anomalies.

Alternative explanations would include fraud, faulty memory, and coincidence. To rule out fraud, one would need to interview Wink to be sure that the dreams as reported by Amanda were identical to the dreams related to Wink. Even so, if there had been collusion, one could not easily determine if Amanda and Wink had concocted the dreams to fit the circumstances of the demise of Wink's buddies. The dream about Jess could have been fabricated based on research concerning the casualties of the U.S. intervention in Panama. The fraud hypothesis needs to be considered, because skeptics could easily dismiss these accounts on that basis alone.

However, the fraud scenario is extremely convoluted. It would have been simpler for Amanda to make up the dreams without bringing in another person, one who-upon questioning - might admit complicity. One must also question the motivation. Dreaming about deceased persons is not the easiest way to garner attention in the contemporary United States. Furthermore, Amanda has made no attempt to use these dreams for commercial gain or publicity purposes. If Amanda's goal had been to embarrass researchers or to gain publicity, she could have done so when she and Wink attended a 2015 conference where I publically presented several of these accounts. Due to logistical problems, they arrived after I had left, but they did have the opportunity to meet other researchers of post-mortem survival and were cordially received. Their choice to go to the time and expense of attending the conference, thereby placing themselves under the scrutiny of these researchers and risking exposure as frauds, mitigates against a conspiracy or fraud hypothesis-unless one further hypothesizes that this military events planner and chaplain's assistant are two sociopaths who found each other and concocted this elaborate scheme with the primary intent of duping researchers. All of these hypotheses are contradicted by my subsequent communication with two of the researchers from the conference, both discerning and alert with regard to fraud, who spoke with Amanda and Wink. They conveyed to me their impressions that Amanda and Wink appeared sincere and unassuming - in other words, credible-and that Amanda and Wink's narratives of their experiences corresponded consistently, both between the two of them and to what I had presented. 
Another alternative explanation would be faulty memory. People's dream reports never capture a dream in its entirety. Could Amanda have started to tell Wink the dream, only to have him intervene and ask, "Could this have been my buddy Hal?" Amanda could then have replied, "Yes, I believe his name was Hal or Howard." Over time, the conversation might have been forgotten and the dream report that was shared with me could have left out its evolution. Although this scenario is possible, it seems highly unlikely that this pattern would have repeated itself several times without either Amanda or Wink becoming aware of it.

It is also possible that Amanda could have heard Wink mention the names of the individuals who appeared in her dreams but then forgot about this exposure. For example, Wink might have mentioned the names in casual conversation, and both of them could have forgotten the incidents. For this explanation to be taken seriously, one would have to propose that Wink (or another person) would have cited these names repeatedly, and then forgot that he had done so. There is nothing in the literature on the incorporation of names into dream content that would provide plausibility to this suggestion.

The third possibility of coincidence is even more unlikely, given the specific names and details involved. However, even the most experienced dream diarist realizes that one remembers only a fraction of one's nighttime dreams. Could other soldiers have contacted Amanda with other messages, but she simply did not recall the dream upon awakening? Could the remembered dream be the second, third, or fourth attempt of the soldier to convey a positive message to Wink? There is no easy answer to these questions, but it appears that these dream messages provided Wink with information that helped alleviate the "survival guilt" common to veterans who returned home lamenting their buddies who did not survive. All things considered, these alternative explanations lack clear explanatory value.

A more viable possibility is putative telepathic contact between Wink and Amanda. She may have unconsciously "picked up" information from him to alleviate his need to be freed of survivor guilt. However, if this dynamic, rather than mediumship, were at work, an anomalous aspect would still be present, even if the survival aspect was not. However, one feature of Amanda's dream (Case Five) argues against this interpretation: the medic who prescribed St. Jessie's Wort to help Wink with PTSD. This feature involved (a) material presumably not already in Wink's memory, and (b) intentionality, which is more characteristic of an existing and purposeful entity than an 
existing memory. In actuality, of course, the substance is St. John's wort.

A related possibility is some other form of so-called "psi" phenomena such as "super-psi" (Kelly, Kelly, Crabtree, Gauld, Grosso, \& Greyson, 2007, p. 597) and the "Akashic field," a proposed web of information that unites human beings both before and after death (e.g., Laszlo, 2000). These explanations are theoretical in nature and defy definitive experimental attempts to confirm or disconfirm them. Kelly et al. (2007) concluded that the issue "cannot be decisively resolved at the present time" (p. 597).

The antecedents of purported mediumship have been studied; they include a variety of predisposing factors ranging from brain syndromes (Beyerstein, 1988) and childhood trauma (Kaminker, 2013) to "fantasy proneness" (Jinks, 2013), "transliminality," the narrow boundary between the external world and one's internal states (Thalbourne, Crawley, \& Houran, 2003), and NDEs (Holden, Foster, \& Kinsey, 2014). Amanda does not refer to herself as a "medium," even though her alleged abilities would evoke this term among many other investigators. Personally, I use the term "claimant mediums" to describe individuals who self-designate themselves as "mediums," and simply note that people like Amanda display "mediumistic qualities," without using a label that might be interpreted as pejorative. In my cross-cultural dream research, I have collected dream reports from individuals who obtained what appears to be veridical information from deceased loved ones (Krippner, Faith, \& Suzuki, 2000) but have not referred to them as "mediums."

In the meantime, we are left with a remarkable story. If the details as presented are accurate, Amanda's collection of dream reports provides useful information relevant to what researchers call "the survival hypothesis" (Rock, 2013). The deceased persons who appeared in Amanda's dreams seemed motivated to contact the living for benevolent purposes. The deceased soldiers presumably could not achieve this goal directly, because their surviving comrade, Wink, was not a suitable conduit. However, Wink's friend Amanda apparently was an excellent conduit: one who enabled them to convey their positive messages quite well. Amanda's decision to share these dreams with a professional researcher rather than a reporter for a tabloid attests to her sincerity and integrity.

Mediumship research has gained remarkable momentum in recent years, but is still a controversial topic in the mainstream scientific community. Mainstream scientists, in general, avoid addressing sev- 
eral important questions: Does sentient consciousness exist external to the human's body-mind consciousness? Are spirits, ghosts, apparitions, deities, ancestor-beings, or spiritual entities real, or are they imaginary characters? If they are imaginary, what is the source of the knowledge that is attributed to them, information that has been put to practical use in advising and guiding living humans for millennia? An equally intriguing question follows: Does the human being have an internal hard-wired capacity to experience other ways of knowing, ways that are attributed to incorporeal entities? If the capacity is hard-wired, what function does the capacity serve? Is the capacity utilitarian in nature, serving an adaptive function in human evolution - or is it a spiritually-oriented capacity that permits people to experience other ways of knowing - or is it a combination of both possibilities?

The literature on after-death communication (ADC) is illustrative in this regard (e.g., Guggenheim \& Guggenheim, 1995). I have written (Krippner, 2006) about the role that ADCs may play in helping surviving friends and family members work through the grief and depression that often occurs after their loved one's passing. ADCs can occur in a number of settings such as waking "visitations" (e.g., a sensed "presence"), telephone calls purportedly from the deceased, or unusual natural phenomena (e.g., rainbows). Guggenheim (2005) found that ADCs tend to be "initiated by deceased loved ones" (p. 5), whereas Parker (2004) and others have found that most experiencers' reports were not signs of psychopathology but, to the contrary, initiated positive changes such as personal and spiritual growth.

Epistemological models have used various terms, such as exceptional experiences, anomalous experiences, psychic experiences, extraordinary experiences, numinous experiences, reincarnation experiences, near-death experiences, shamanic experiences, mediumship experiences, trance channeling, spiritualism, spiritistic practices, esoteric and faith-based practices, religious-based charismatic practices, and indigenous practices, to name a few. All of these models have been used to explore the possibility of life after death-a core belief in the mediumship practice, and each these models has been used to examine the idea of consciousness being external to the human body-mind, at least at times. In addition, some of these models have focused on understanding and describing the mental health of individuals who have reported these experiences or in explaining the phenomenology of the experiences.

On the other hand, the future of mediumship research may take the 
less controversial path of describing individuals' experiences without addressing the underlying epistemological and philosophical issues, even though these issues are at the core of the scientific community's frequent rejection of mediumship research as a viable and worthwhile focus for serious investigation. Methodologies that focus on personality traits; lifestyles of mediums-including their values, attitudes, and interests; and the development of mediumship may all help to expand the understanding of mediumship and those who practice it. My investigation of Amanda's putative spontaneous mediumship has taken this route, focusing on her lived experience and its precursors. In addition, I have been interested in the neuroscience of mediumship and, with Harris Friedman, edited a book in which we attempted to pull together the sparse literature on the neurobiology of mediumship and similar extraordinary experiences (Krippner \& Friedman, 2010).

However, it is questionable that these methodologies encompass a framework that would address the epistemological and philosophical issues in how to capture and study phenomena that may be external to the human body-mind consciousness. A useful strategy would be to attempt advances on both fronts, to use conventional methodologies to describe mediums and their practice of mediumship while searching for novel methodologies to address more controversial issues. Advanced brain technology might be useful to delineate how this engagement is accomplished. In the meantime, as mentioned earlier, the term "claimant medium" is a useful descriptor of men and women who claim to contact the other, as the term is non-pejorative, and makes no assumptions about the reality or unreality, the integrity or lack of integrity, or the veridicality or non-veridicality of the research participant and the information that is forthcoming from a mediumistic session. Amanda's dreams may play an important role in connecting the links between dream reports, mediumistic experiences, and the possibility of life after death. However, the possibility of alternative scenarios, including collusion between Amanda and Wink, demonstrate the need for rigor and caution when conducting these types of investigations.

\section{References}

Beyerstein, B. L. (1988, Spring). Neuropathology and the legacy of spiritual possession. Skeptical Inquirer, 12(3), 248-264.

Guggenheim, B. (2005). After-death communication: A new field of research confirms that life and love are eternal. Abstracts of Presentations, 30th Annual 
Conference of the Academy of Religion and Psychical Research, Orlando, FL (p. 5). Bloomfield, CT: Academy of Religion and Psychical Research.

Guggenheim, B., \& Guggenheim, J. (1995). Hello from heaven. New York, NY: Bantam.

Holden, J. M., Foster, R. D., \& Kinsey, L. (2014). Spontaneous mediumship experiences: A neglected aftereffect of near-death experiences. Journal of NearDeath Studies, 33(2), 67-85.

Jinks, T. (2013). The psychology of belief in discarnate communication. In A. J. Rock (Ed.), The survival hypothesis: Essays on mediumship (pp. 90-106). Jefferson, NC: McFarland.

Kaminker, J. (2013). Mediumship and psychopathology. In A. J. Rock (Ed.), The survival hypothesis: Essays on mediumship (pp. 146-159). Jefferson, NC: McFarland.

Kelly, E. F., Kelly, E. W., Crabtree, A., Gauld, A., Grosso, M., \& Greyson, B. (2007). Irreducible mind: Toward a psychology for the 21st century. Lanham, MD: Rowman and Littlefield.

Krippner, S. (2006). Getting through the grief: After-death communication experiences and their effects on experients. In L. Storm \& M. A. Thalbourne (Eds.), The survival of human consciousness (pp. 174-193). Jefferson, NC: McFarland.

Krippner, S., Bogzaran, F., \& de Carvalho, A. P. (2002). Extraordinary dreams and how to work with them. Albany, NY: State University of New York Press.

Krippner, S., Faith, L., \& Suzuki, Y. (2000). National and gender differences in reports of exotic dreams. Dream Network, 19(1), 40-42.

Krippner, S., \& Friedman, H. (Eds.). (2010). Mysterious minds: The neurobiology of psychics, mediums, and other extraordinary people. Santa Barbara, CA: ABC-CLIO.

O'Keefe, C., \& Wiseman, R. (2005). Testing alleged mediumship: Methods and results. British Journal of Psychology, 96, 165-179.

Parker, J. S. (2004). After-death communication experiences and adaptive grief outcomes. (Unpublished doctoral dissertation). San Francisco, CA: Saybrook Graduate School and Research Center.

Rock, A. J. (Ed.). (2013). The survival hypothesis: Essays on mediumship. Jefferson, NC: McFarland.

Schouten, S. A. (1994). An overview of quantitatively evaluated studies with mediums and psychics. Journal of the American Society for Psychical Research, $88,221-254$.

Stemman, R. (2005). Spirit communication: A comprehensive guide to the extraordinary world of mediums, psychics and the afterlife. London, England, UK: Piatkus Books.

Streit-Horn, J. (2011). A systematic review of research on after-death communication (Doctoral dissertation). Retrieved from http://digital.library.unt.edu/ ark:/67531/metadc84284/m1/

Thalbourne, M., Crawley, S. E., \& Houran, J. (2008). Temporal lobe lability in the highly transliminal mind. Personality and Individual Differences, 1, 180-185. 